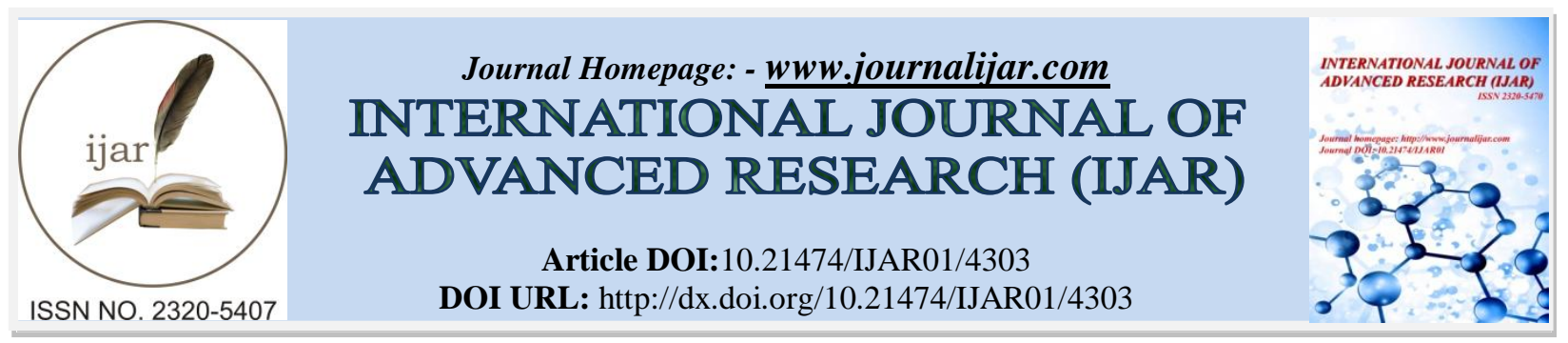

RESEARCH ARTICLE

\title{
MEASUREMENT OF EFFECTIVE ATOMIC NUMBER AND ELECTRON DENSITY OF CARBOHYDRATES BY USING NIST, Geant4 AND NaI(TI) : A COMPARATIVE STUDY.
}

*Rajkumar M. Lokhande, Bharat S. Surung and Pravina P. Pawar.

Department of Physics, Dr. Babasaheb Ambedkar Marathwada University, Aurangabad, 431004 India.

\section{Manuscript Info}

Manuscript History

Received: 19 March 2017

Final Accepted: 23 April 2017

Published: May 2017

Key words:-

Mass attenuation coefficient $\left(\mu_{\mathrm{m}}\right)$,

Effective atomic number $\left(\mathrm{Z}_{\mathrm{eff}}\right)$, Effective

electron density $\left(\mathrm{N}_{\mathrm{eff}}\right)$, Geant4

simulation

\section{Abstract}

The Monte Carlo simulation applying for calculation of mass attenuation coefficient, total attenuation cross section, electronic cross section, effective atomic number $\left(\mathrm{Z}_{\text {eff }}\right)$, effective electron density $\left(\mathrm{N}_{\text {eff }}\right)$ at incident photon energy $122 \mathrm{keV}, 360 \mathrm{keV}, 511 \mathrm{keV}, 662 \mathrm{keV}, 840$ $\mathrm{keV}, 1170 \mathrm{keV}, 1275 \mathrm{keV}$ and $1330 \mathrm{keV}$ of Fructose, Maltose, Cellulose, Sorbitol, Raffinose, Xylose carbohydrates. We used narrow beam geometry $\mathrm{NaI}(\mathrm{Tl})$ scintillation detector with $8 \mathrm{~K}$ multichannel analyser having resolution $8.2 \%$ at $662 \mathrm{keV}$. The $\mathrm{Z}_{\text {eff }}$ and $\mathrm{N}_{\text {eff }}$ results experimentally by $\mathrm{NaI}(\mathrm{Tl})$ scintillation detector compared with Geant 4 monte carlo simulation observed less uncertainties. We observed that Geant4 simulation important toolkit of radiation measurement for biological material and especially medical diagnosis.

Copy Right, IJAR, 2017,. All rights reserved.

\section{Introduction:-}

The ionizing radiation effect on biological material such as amino acid, carbohydrates, lipids, fatty acids depends on the absorbed dose. Data on the transmission and absorption of gamma ray in biological, shielding and dosimetric materials assumes great significance by virtue their diverse application in the field of radiation physics, radiation biology, agriculture, industry, medical, radiation dosimetry, diagnosis, shielding, gamma ray fluorescence, drug delivery, radiation biophysics, science and technology. Mass attenuation coefficient $\left(\mu_{\mathrm{m}}\right)$, effective atomic number $\left(\mathrm{Z}_{\mathrm{eff}}\right)$, total attenuation cross section, total electronic cross section, effective electron density $\left(\mathrm{N}_{\mathrm{eff}}\right)$, are basic parameter to finding the penetration and energy deposition of gamma radiation [1-9].The theoretical value of the mass attenuation coefficient tabulated of all Elements, mixture and compounds over $1 \mathrm{eV}$ to $100 \mathrm{GeV}$ photon energy ranges [10]. The selected photon energy ranges from $122 \mathrm{keV}$ to $1500 \mathrm{keV}$ are basically used in the medical and biological application during the diagnosis and radiotherapy.The geant4 code freely available http://geant4.fweb.cern.ch/geant4. GEANT4 (GEometry ANd Tracking) simulations used in the field of high energy physics (HEP), atomic nucleus, elementary particles and technology, it gives detail study about radiation interaction with matter. This code applicable for various fields such as radiation physics, radiation biology, medical physics, radio sensitization [11]. The mass energy absorption coefficient and karma of $\mathrm{C}, \mathrm{N}, \mathrm{Si}, \mathrm{NaI}$ calculated Steel alloy a comparative study, composite material a comparative study of Monte Carlo simulation with experimental and theoretical workmeasuring the efficiency of germanium detector using by Geant 4 simulation[12-15]. Geant4 Monte Carlo simulation for photon interaction with matter especially electromagnetic physics and interaction process i.e. Photoelectric, Compton, Pair production gives detail study [16].The mass attenuation coefficient of saccharides and amino acids calculated at lower energy, this energy is very useful in medical diagnosis and radiation therapy [1718]. The atomic number of composite material is depending on the energy, i.e. atomic number of composite material 
decreases with increasing incident photon energy it reflects a number cannot show atomic number of the composite material in entire energy region is called as effective atomic number [19-20].

A variety of physiological functions in the human living system are performed by complex molecule such as amino acid, carbohydrate, protein, fats and oils composed of $\mathrm{C}, \mathrm{H}, \mathrm{N}, \mathrm{O}$ element based. Carbohydrates were the most important class of biological material in a living system. It contains sugar, starch, cellulose.

The present study has been shown the validation of Geant 4 Monte Carlo simulation compared with experimentally narrow beam geometry and theoretical NIST XCOM database at selected energy region. The study has been undertaken to get information of the mass attenuation coefficient $\left(\mu_{\mathrm{m}}\right)$, total attenuation cross section, total electronic cross section, molar extinction coefficient, effective atomic number $\left(\mathrm{Z}_{\text {eff }}\right)$, effective electron density $\left(\mathrm{N}_{\text {eff }}\right)$, of the selected carbohydrates with Geant4 monte carlo method. Novelty of present study was to first time applied Geant 4 Monte Carlo simulation for measurement of effective atomic number $\left(\mathrm{Z}_{\mathrm{eff}}\right)$ and electron density $\left(\mathrm{N}_{\text {eff }}\right)$ of the C-H-N$\mathrm{O}$ based biological material. We were investigating Geant 4 simulation one of the best alternative method for radiation measurement.

\section{Theory:-}

\section{Mass Attenuation coefficient:-}

The measurement of mass attenuation coefficient of the carbohydrates was performed for homogeneous medium by using Lambert Beer exponential attenuation law,

$$
I=I_{0} e^{\mu x}(1)
$$

Where $I_{0}$ and $I$ are the unattenuated and attenuated photon intensity respectively, $\mu$ is the linear attenuation coefficient; $\mathrm{X}$ is the thickness of the sample. The ratio of linear attenuation coefficients and density of material called as mass attenuation coefficients $\left(\mu_{\mathrm{m}}\right)$.

Total atomic cross section:-

Firstly, we calculate the total attenuation cross section

$$
\sigma_{t}=\frac{1}{N_{A}} \sum f_{i} A_{i}\left(?_{m}\right)
$$

$\mathrm{N}_{\mathrm{A}}$ is the Avogadro constant, $\mu_{\mathrm{m}}$ is the mass attenuation coefficient and $\mathrm{A}_{\mathrm{i}}$ is the molar mass of the sample. $\sum \mathrm{f}_{\mathrm{i}}=1$ $\left(f_{i}\right.$ is the mole fraction).

\section{Electronic cross section:-}

$$
\sigma_{e}=\frac{1}{N_{A}} \sum_{i} \frac{f_{i} A_{i}}{Z_{i}}\left(\square_{m}\right)_{i}=\frac{\sigma_{t}}{\sum Z_{e f f}}(4)
$$

Electronic cross section is the ratio of total attenuation cross section and effective atomic number shows in above written formula.

The effective atomic number $\left(Z_{\text {eff }}\right)$ :Compton scattering interaction process of the composite material depends on effective atomic number, which is discussed by [19]

$$
Z_{\text {eff }}=\frac{\sigma_{t}}{\sigma_{e}}(\mathbf{5})
$$

\section{Effective Electron Density:-}

Effective electron density shows that the number of electron per unit mass

$$
N_{\text {eff }}=\left(\frac{N_{A}}{A_{\text {eff }}}\right) * Z_{\text {eff }}
$$

$\mathrm{A}_{\text {eff }}$ is effective atomic mass also known as the ratio of atomic weight and total number of atom

\section{Experimental detail:-}

The radioactive sources ${ }^{57} \mathrm{Co},{ }^{133} \mathrm{Ba},{ }^{137} \mathrm{Cs},{ }^{54} \mathrm{Mn},{ }^{22} \mathrm{Na}$ and ${ }^{60} \mathrm{Co}$ were used to generate gamma rays for the experiment. The gamma ray energies emitted by these sources are $122 \mathrm{keV}, 360 \mathrm{keV}, 511 \mathrm{keV}, 662 \mathrm{keV}, 840 \mathrm{keV}$, $1170 \mathrm{keV}, 1275 \mathrm{keV}$ and $1330 \mathrm{keV}$ respectively. Gamma rays emitted by these radioactive sources were collimated and detected by the $\mathrm{NaI}(\mathrm{Tl})$ scintillation detector. The sources are perpendicular to the surface of the material. The selected gamma ray spectroscopic system was the narrow beam geometry shown in fig 1 . As the high $\mathrm{Z}$ of iodine in 
$\mathrm{NaI}$ have good efficiency [21]. The signals from the detector (2" $\times 2$ ") $\mathrm{NaI}(\mathrm{Tl})$ crystal having energy resolution of $8.2 \%$ at $662 \mathrm{keV}$ gamma rays from the decay of $\mathrm{Cs}^{137}$ after suitable amplification according to full width at half maxima FWHM was recorded in EG\&G ORTEC 13-bit plug-in-card coupled to a PC/AT. The stability and reproducibility of the arrangement were checked before and after each set of runs in the usual manner. The system shows fine acquires gamma ray spectra to provide accurate information at below room temperature $\left(20{ }^{\circ} \mathrm{C}\right.$ to $\left.23{ }^{\circ} \mathrm{C}\right)$. All materials had good purity $(99 \%)$. The sample thickness was selected in order to satisfy the following ideal condition as far as possible [22].The pellet of material was prepared by using $\mathrm{KBr}$ press machine (up to pressure 10 ton) with $0.20 \mathrm{~g} / \mathrm{cm}^{2}$ of uniform thicknesses and confined in a cylindrical plastic container having the same diameter as that of sample pellets. The diameters of the samples were determined with the help of a travelling microscope. Weights of pallet were measured by using digital balance having $0.001 \mathrm{mg}$ accuracy. We measured value of $\mathrm{I}_{0}$ (unattenuated photon intensity) with empty plastic container and I (attenuated photon intensity) with sample at narrow beam geometry set up. The mass attenuation coefficient $\left(\mu_{\mathrm{m}}\right)$ for all carbohydrate group material was calculated using eq. (1) and theoretically observed by NIST XCOM database at selected incident photon energy. Proper adjustment of the distance between the detector and source $(30 \mathrm{~cm} \leq \mathrm{d} \leq 50 \mathrm{~cm})$, the maximum angle of scattering was below $30 \mathrm{~min}$. In the multichannel analyzer used in the present study, there was a built-in provision for dead time correction.

\section{Geant4 Simulation:-}

Geant4 Monte Carlo simulation method based on object oriented C++ programming language, it is used for measurement of radiation interaction with matter at wide energy range $250 \mathrm{eV}$ to $100 \mathrm{TeV}$. Geant 4 method for electromagnetic package was especially applied for narrow beam geometry. We were calculated mass attenuation coefficient using computer environment and Geant4 applications G4RunManager for low energy physics Electromagnetic Standard G4PhotoElectricEffect, G4ComptonScattering, G4GammaConversion (pair production). We have known the primary information of electromagnetic package for Geant 4 simulation. First stage construction, narrow beam geometry set up and set distance between source-sample-detector. Second stage set energy, chemical composition, density, elemental weight fraction and thicknesses of material, set physical process corresponding to photon energy. Third stage measured simulation value by using GMcalculator after $10^{6}$ times hits of gamma radiation on selected material at particular thickness.

Table 1:- The mean atomic numbers calculated from the chemical formula for the investigated carbohydrates.

\begin{tabular}{|c|c|c|c|c|c|}
\hline & carbohydrates & Chemical Formula & Mean Atomic Number & Molar Mass $(\mathrm{g} / \mathrm{mol})$ & $A_{\text {eff }}$ \\
\hline 1 & Fructose & $\mathrm{C}_{6} \mathrm{H}_{12} \mathrm{O}_{6}$ & 4.00 & 180.16 & 7.5067 \\
\hline 2 & Maltose & $\mathrm{C}_{12} \mathrm{H}_{22} \mathrm{O}_{11}$ & 4.04 & 342.30 & 7.6067 \\
\hline 3 & Cellulose & $\mathrm{C}_{6} \mathrm{H}_{10} \mathrm{O}_{5}$ & 4.10 & 342.30 & 16.2998 \\
\hline 4 & Sorbitol & $\mathrm{C}_{6} \mathrm{H}_{14} \mathrm{O}_{6}$ & 3.77 & 182.17 & 7.0065 \\
\hline 5 & Raffinose & $\mathrm{C}_{18} \mathrm{H}_{32} \mathrm{O}_{16}$ & 4.06 & 504.42 & 7.6427 \\
\hline 6 & Xylose & $\mathrm{C}_{5} \mathrm{H}_{10} \mathrm{O}_{5}$ & 4.00 & 150.13 & 7.5065 \\
\hline
\end{tabular}

Table 2:- Mass attenuation coefficient $\left(\mathrm{cm}^{2} / \mathrm{g}\right)$ for the investigated carbohydrates.

\begin{tabular}{|c|l|r|r|r|r|r|r|r|}
\hline Energy (keV) & & 122 & 356 & 511 & 662 & 1170 & 1275 & 1330 \\
\hline Fructose & Geant4 & 0.1496 & 0.1062 & 0.0923 & 0.0827 & 0.0631 & 0.0603 & 0.0590 \\
\hline & xcom & 0.1546 & 0.1059 & 0.0926 & 0.0839 & 0.0661 & 0.0599 & 0.0595 \\
\hline & $\mathrm{NaI}(\mathrm{Tl})$ & 0.1424 & 0.1048 & 0.0892 & 0.0815 & 0.0646 & 0.0603 & 0.0570 \\
\hline & Geant4 & 0.1492 & 0.1060 & 0.0921 & 0.0826 & 0.0629 & 0.0602 & 0.0589 \\
\hline & xcom & 0.1542 & 0.1056 & 0.0924 & 0.0837 & 0.0659 & 0.0598 & 0.0593 \\
\hline & $\mathrm{NaI}(\mathrm{Tl})$ & 0.1428 & 0.1028 & 0.0902 & 0.0824 & 0.0634 & 0.0597 & 0.0569 \\
\hline Maltose & Geant4 & 0.1489 & 0.1057 & 0.0919 & 0.0824 & 0.0628 & 0.0600 & 0.0587 \\
\hline & xcom & 0.1538 & 0.1054 & 0.0922 & 0.0835 & 0.0658 & 0.0596 & 0.0592 \\
\hline & $\mathrm{NaI}(\mathrm{Tl})$ & 0.1404 & 0.1035 & 0.0907 & 0.0811 & 0.0643 & 0.0595 & 0.0572 \\
\hline & Geant4 & 0.1510 & 0.1072 & 0.0932 & 0.0835 & 0.0637 & 0.0609 & 0.0596 \\
\hline & xcom & 0.1560 & 0.1069 & 0.0935 & 0.0847 & 0.0667 & 0.0605 & 0.0600 \\
\hline & $\mathrm{NaI}(\mathrm{Tl})$ & 0.1468 & 0.1048 & 0.0912 & 0.0835 & 0.0652 & 0.0583 & 0.0585 \\
\hline & Geant4 & 0.1491 & 0.1059 & 0.0921 & 0.0825 & 0.0629 & 0.0601 & 0.0588 \\
\hline & xcom & 0.1541 & 0.1056 & 0.0923 & 0.0836 & 0.0659 & 0.0597 & 0.0593 \\
\hline & NaI(Tl) & 0.1372 & 0.0981 & 0.0904 & 0.0801 & 0.0604 & 0.0578 & 0.0569 \\
\hline & Geant4 & 0.1496 & 0.1062 & 0.0923 & 0.0827 & 0.0631 & 0.0603 & 0.0590 \\
\hline
\end{tabular}




\begin{tabular}{|l|l|r|r|r|r|r|r|r|}
\hline & xcom & 0.1546 & 0.1059 & 0.0926 & 0.0839 & 0.0661 & 0.0599 & 0.0595 \\
\hline & $\mathrm{NaI}(\mathrm{Tl})$ & 0.1420 & 0.1031 & 0.0893 & 0.0818 & 0.0647 & 0.0569 & 0.0565 \\
\hline
\end{tabular}

Table 3:- Effective atomic number, $Z_{\text {eff }}$ of the investigated carbohydrates.

\begin{tabular}{|c|c|c|c|c|c|c|c|c|}
\hline Energy $(\mathrm{keV})$ & & 122 & 356 & 511 & 662 & 1170 & 1275 & 1330 \\
\hline \multirow{2}{*}{ Fructose } & Geant4 & 4.0000 & 4.0000 & 4.0000 & 4.0000 & 4.0000 & 4.0000 & 4.0000 \\
\cline { 2 - 9 } & NaI(Tl) & 4.0224 & 4.0097 & 4.0055 & 4.0024 & 3.9957 & 3.9947 & 3.9942 \\
\hline & $\%$ Error & -0.5569 & -0.2419 & -0.1373 & -0.0600 & 0.1076 & 0.1327 & 0.1452 \\
\hline \multirow{3}{*}{ Maltose } & Geant4 & 4.0444 & 4.0444 & 4.0444 & 4.0444 & 4.0444 & 4.0444 & 4.0444 \\
\cline { 2 - 9 } & NaI(Tl) & 4.0815 & 4.0660 & 4.0607 & 4.0570 & 4.0487 & 4.0475 & 4.0469 \\
\hline & \%Error & -0.9090 & -0.5312 & -0.4014 & -0.3106 & -0.1062 & -0.0766 & -0.0618 \\
\hline \multirow{3}{*}{ Cellulose } & Geant4 & 4.0952 & 4.0952 & 4.0952 & 4.0952 & 4.0952 & 4.0952 & 4.0952 \\
\cline { 2 - 9 } & NaI(Tl) & 4.0815 & 4.0660 & 4.0607 & 4.0570 & 4.0487 & 4.0475 & 4.0469 \\
\hline & \%Error & 0.3357 & 0.7182 & 0.8496 & 0.9416 & 1.1485 & 1.1785 & 1.1935 \\
\hline \multirow{2}{*}{ Sorbitol } & Geant4 & 3.7692 & 3.7692 & 3.7692 & 3.7692 & 3.7692 & 3.7692 & 3.7692 \\
\cline { 2 - 9 } & NaI(Tl) & 3.7279 & 3.7291 & 3.7295 & 3.7298 & 3.7305 & 3.7306 & 3.7306 \\
\hline \multirow{2}{*}{ Raffinose } & \%Error & 1.1079 & 1.0753 & 1.0645 & 1.0564 & 1.0374 & 1.0347 & 1.0347 \\
\hline & Geant4 & 4.0606 & 4.0606 & 4.0606 & 4.0606 & 4.0606 & 4.0606 & 4.0606 \\
\cline { 2 - 9 } & NaI(Tl) & 4.1029 & 4.0863 & 4.0807 & 4.0767 & 4.0679 & 4.0665 & 4.0659 \\
\hline & $\%$ Error & -1.0310 & -0.6289 & -0.4926 & -0.3949 & -0.1795 & -0.1451 & -0.1304 \\
\hline Xylose & Geant4 & 4.0000 & 4.0000 & 4.0000 & 4.0000 & 4.0000 & 4.0000 & 4.0000 \\
\cline { 2 - 8 } & NaI(Tl) & 4.0223 & 4.0096 & 4.0054 & 4.0023 & 3.9956 & 3.9946 & 3.9941 \\
\hline & $\%$ Error & -0.5544 & -0.2394 & -0.1348 & -0.0575 & 0.1101 & 0.1352 & 0.1477 \\
\hline
\end{tabular}

Table 4:- Effective electron densities, $\mathrm{N}_{\text {eff }}\left(10^{23}\right.$ electrons/g) for the investigated carbohydrates.

\begin{tabular}{|c|c|c|c|c|c|c|c|c|}
\hline \multicolumn{2}{|c|}{ Energy (keV) } & 122 & 356 & 511 & 662 & 1170 & 1275 & 1330 \\
\hline & Geant4 & 3.1859 & 3.1759 & 3.1725 & 3.1701 & 3.1648 & 3.1640 & 3.1636 \\
\hline \multirow[t]{3}{*}{ Fructose } & $\mathrm{NaI}(\mathrm{Tl})$ & 3.2104 & 3.2104 & 3.2104 & 3.2104 & 3.2104 & 3.2104 & 3.2104 \\
\hline & \%Error & -0.7631 & -1.0746 & -1.1805 & -1.2553 & -1.4204 & -1.4453 & -1.4578 \\
\hline & Geant4 & 3.2328 & 3.2204 & 3.2163 & 3.2133 & 3.2068 & 3.2058 & 3.2053 \\
\hline \multirow[t]{3}{*}{ Maltose } & $\mathrm{NaI}(\mathrm{Tl})$ & 3.2034 & 3.2034 & 3.2034 & 3.2034 & 3.2034 & 3.2034 & 3.2034 \\
\hline & \%Error & 0.9178 & 0.5307 & 0.4027 & 0.3090 & 0.1061 & 0.0749 & 0.0593 \\
\hline & Geant4 & 2.9854 & 2.9854 & 2.9854 & 2.9854 & 2.9854 & 2.9854 & 2.9854 \\
\hline \multirow[t]{3}{*}{ Cellulose } & $\mathrm{NaI}(\mathrm{Tl})$ & 3.2436 & 3.2436 & 3.2436 & 3.2436 & 3.2436 & 3.2436 & 3.2436 \\
\hline & \%Error & -7.9603 & -7.9603 & -7.9603 & -7.9603 & -7.9603 & -7.9603 & -7.9603 \\
\hline & Geant4 & 3.2056 & 3.2066 & 3.2070 & 3.2072 & 3.2078 & 3.2079 & 3.2079 \\
\hline \multirow[t]{3}{*}{ Sorbitol } & $\mathrm{NaI}(\mathrm{Tl})$ & 3.2411 & 3.2411 & 3.2411 & 3.2411 & 3.2411 & 3.2411 & 3.2411 \\
\hline & \%Error & -1.0953 & -1.0645 & -1.0521 & -1.0459 & -1.0274 & -1.0243 & -1.0243 \\
\hline & Geant4 & 3.2010 & 3.2010 & 3.2010 & 3.2010 & 3.2010 & 3.2010 & 3.2010 \\
\hline \multirow[t]{3}{*}{ Raffinose } & $\mathrm{NaI}(\mathrm{Tl})$ & 3.2343 & 3.2212 & 3.2168 & 3.2137 & 3.2067 & 3.2057 & 3.2052 \\
\hline & \%Error & -1.0296 & -0.6271 & -0.4912 & -0.3952 & -0.1778 & -0.1466 & -0.1310 \\
\hline & Geant4 & 3.2105 & 3.2105 & 3.2105 & 3.2105 & 3.2105 & 3.2105 & 3.2105 \\
\hline \multirow[t]{2}{*}{ Xylose } & $\mathrm{NaI}(\mathrm{Tl})$ & 3.2284 & 3.2182 & 3.2148 & 3.2123 & 3.2070 & 3.2061 & 3.2057 \\
\hline & \%Error & -0.5545 & -0.2393 & -0.1338 & -0.0560 & 0.1091 & 0.1372 & 0.1497 \\
\hline
\end{tabular}




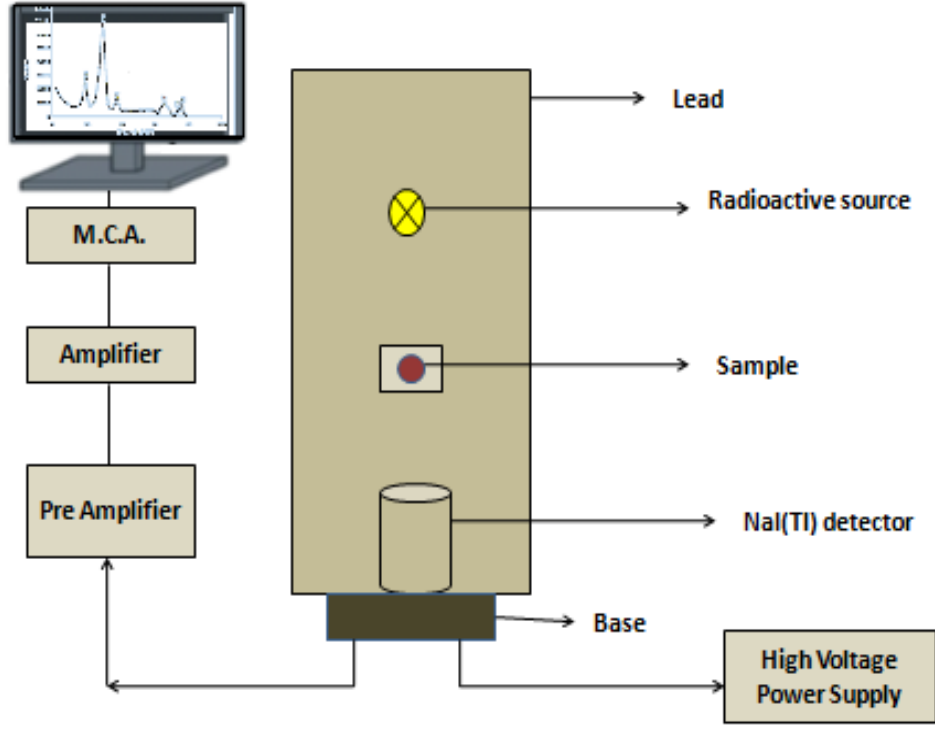

Figure 1:- The schematic view of narrow beam geometry of $\mathrm{NaI}(\mathrm{Tl})$ Detector.

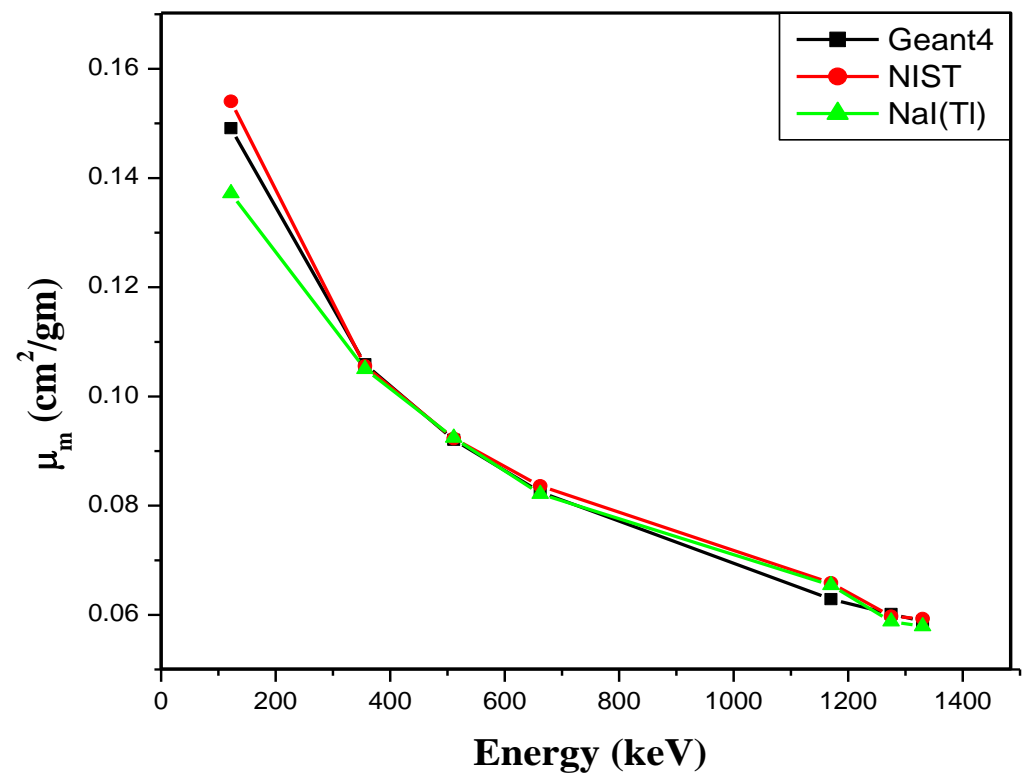

Figure 2:-The typical plot of $\mu_{\mathrm{m}}$ versus Energy (E) for Raffinose $\left(\mathrm{C}_{18} \mathrm{H}_{32} \mathrm{O}_{16}\right)$. 


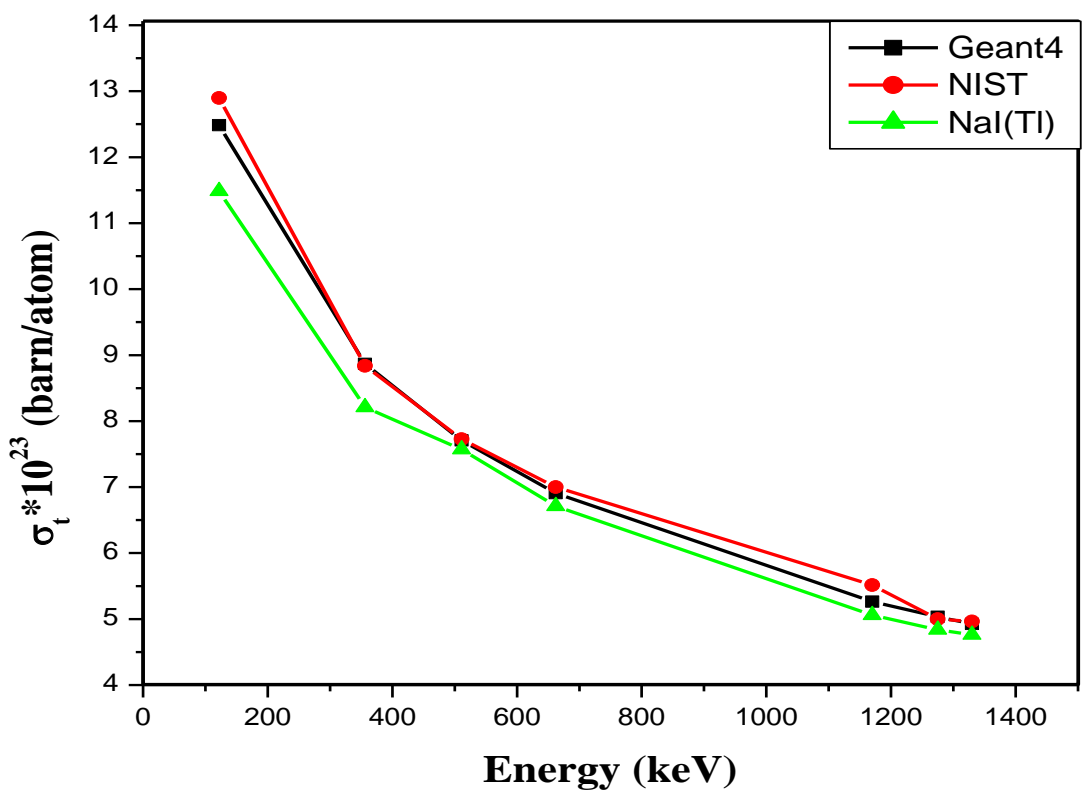

Figure 3:- The typical plot of $\sigma_{\mathrm{t}}$ versus Energy (E) for Raffinose $\left(\mathrm{C}_{18} \mathrm{H}_{32} \mathrm{O}_{16}\right)$.

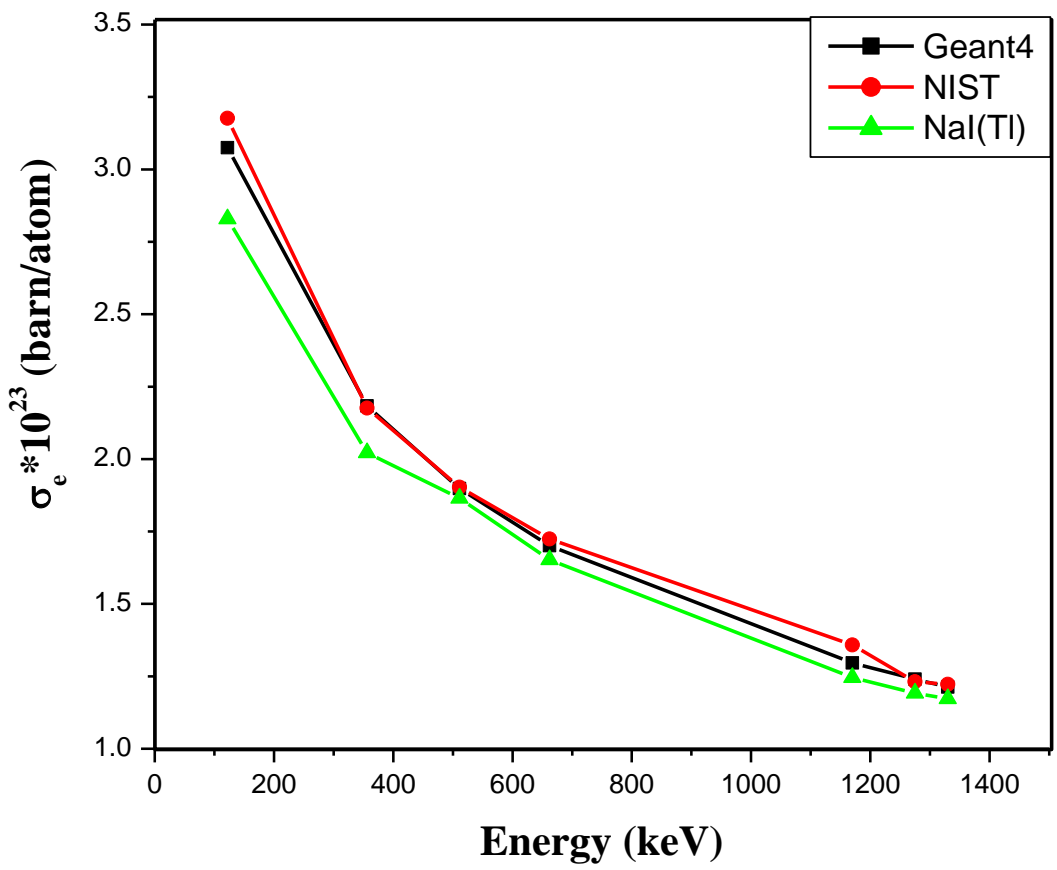

Figure 4:-The typical plot of $\sigma_{\mathrm{e}}$ versus Energy (E) for Raffinose $\left(\mathrm{C}_{18} \mathrm{H}_{32} \mathrm{O}_{16}\right)$.

\section{Result and Discussion:-}

Comparative NIST XCOM, Geant4 simulation theoretically and experimentally using $\mathrm{NaI}(\mathrm{Tl})$ narrow beam geometry study of gamma photon interaction with selected carbohydrates Fructose $\left(\mathrm{C}_{6} \mathrm{H}_{12} \mathrm{O}_{6}\right)$, Maltose $\left(\mathrm{C}_{12} \mathrm{H}_{22} \mathrm{O}_{11}\right)$, Cellulose $\left(\mathrm{C}_{6} \mathrm{H}_{10} \mathrm{O}_{5}\right)$, Sorbitol $\left(\mathrm{C}_{6} \mathrm{H}_{14} \mathrm{O}_{6}\right)$, Raffinose $\left(\mathrm{C}_{18} \mathrm{H}_{32} \mathrm{O}_{16}\right)$, Xylose $\left(\mathrm{C}_{5} \mathrm{H}_{10} \mathrm{O}_{5}\right)$ at $122 \mathrm{keV}-1330 \mathrm{keV}$ incident photon energy. The table 1 shows the chemical and physical parameter of the sample such as mean atomic number $<\mathrm{Z}>$, molar mass and effective atomic mass calculated by using standard formulae. We studied photon interaction parameter such as the mass attenuation coefficient, total atomic cross section, total electronic cross section, effective atomic number and effective electron density of selected carbohydrate material. The mass attenuation coefficient measured by using Geant 4 Monte Carlo simulation this result compared with the NIST XCOM data base and result obtaining from experimental data was determined at 122, 356, 511, 662, 1170,1170, 1275, $1330 \mathrm{keV}$ photons using 
the gamma transmission method by $\mathrm{NaI}(\mathrm{Tl})$ narrow beam geometry source-sample-detector set up shown in figure 1 . In the selected energy Compton scattering is main interaction process, i.e. Compton scattering is dominance in this selected energy region and photoelectric effect is prominent.

The mass attenuation coefficient of carbohydrates study tabulated in table 2 and graphically represent in figure 2 . We observe the mass attenuation coefficient measured from NIST XCOM, Geant4 Monte Carlo simulation and experimentally by $\mathrm{NaI}(\mathrm{Tl})$ narrow beam geometry values with respect to incident photon energy were nearly equal to each other. The mass attenuation coefficient was sharply decreased with increasing incident photon energy. It shows the mass attenuation coefficient is depending on the incident photon energy and chemical composition of the material. The $\mu_{\mathrm{m}}$ is most important basic physical quantity for radiotherapy, medical physics, radio sensitization and computations of radiation measurement quantities.

The theoretical information about total attenuation cross section and electronic cross section by using the mass attenuation coefficient (Geant4, XCOM and $\mathrm{NaI}(\mathrm{Tl})$ scintillation detector) calculates from equation 3 and 4. Graphically in figure 3 and 4 shows the value of the total attenuation cross section and electronic cross section was linearly decreased with photon energy increased of the carbohydrate. The parameter total and electronic cross sections having main purpose to measuring the distribution of photon flux in the object. The table 3 and table 4 gives information about effective atomic number and effective electron density of the material. It shows no change in $\mathrm{Z}_{\text {eff }}$ and $\mathrm{N}_{\text {eff }}$ in the selected energy region. It indicate no change in $\mathrm{Z}_{\text {eff }}$ calculated by using Geant $4 / \mathrm{NaI}(\mathrm{Tl})$ scintillation detector, it reflects that Compton scattering was main interaction process their multiple scattering occur that's why photon living longer time in material. Our result compares with other literature gives same information photon energy increases the $Z_{\text {eff }}$ was decreased, but their Compton scattering was main interaction process their $Z_{\text {eff }}$ remain constant. The $\mathrm{Z}_{\text {eff }}$ calculated by using $\mathrm{NaI}(\mathrm{Tl})$ detector results compared with Geant 4 monte carlo simulation method results it gives same information on the selected energy region. The $\mathrm{Z}_{\mathrm{eff}}$ and $\mathrm{N}_{\text {eff }}$ error found between Geant 4 simulation and $\mathrm{NaI}(\mathrm{Tl})$ scintillation detector at 122- $1330 \mathrm{keV}$ for all carbohydrates shown in table 3 and 4 . We measured error in between Geant 4 and $\mathrm{NaI}(\mathrm{Tl})$ by using eq

$$
\% \text { Error }=\frac{\mathrm{Z}_{\text {eff }}[\text { Geant } 4]-\mathrm{Z}_{\text {eff }}[\mathrm{NaI}(\mathrm{Tl})]}{\mathrm{Z}_{\mathrm{eff}}[\mathrm{NaI}(\mathrm{Tl})]} * 100
$$

We observed that the Geant4 simulation method was valid for measuring $\mathrm{Z}_{\text {eff }}$ of $\mathrm{C}-\mathrm{H}-\mathrm{N}-\mathrm{O}$ based material. We observed the highest electron density of the Raffinose was $3.23 * 10^{23}$ at $122 \mathrm{keV}$, it depends on the increasing total and electronic cross section this study reflects the classification of tumor i.e. effected tumor having a higher electron density than other tissue [23]. The use of $\mathrm{Z}_{\mathrm{eff}}$ for the medical and biological application and the $\mathrm{N}_{\text {eff }}$ which used for measuring distribution of photon or deposition of photon in biological, shielding and dosimetric material [24].

\section{Conclusion:-}

We performed experiment using $\mathrm{NaI}(\mathrm{Tl})$ narrow beam geometry set up at $122 \mathrm{keV}, 360 \mathrm{keV}, 511 \mathrm{keV}, 662 \mathrm{keV}$, $840 \mathrm{keV}, 1170 \mathrm{keV}, 1275 \mathrm{keV}$ and $1330 \mathrm{keV}$ photon energy from carbohydrates. We have done work with Geant4 Monte Carlo simulation at selected energy region. Experimental measured mass attenuation coefficient $\left(\mu_{\mathrm{m}}\right)$, total attenuation cross section $\left(\sigma_{\mathrm{t}}\right)$, electronic cross section $\left(\sigma_{\mathrm{e}}\right)$ comparing with Geant 4 Monte Carlo simulation and NIST standard data base having good agreement with each other. The important part of this study is experimentally measured and simulated value of the effective atomic number and the effective electron density cannot shows the variation in a given energy region. We calculate effective atomic number from eq. 6 was also agreed with available data having less error. We conclude that Geant4 is a useful simulation toolkit in medical radiation, biophysics and theoretically $\mathrm{Z}_{\text {eff }}$ ill be calculated for C-H-N-O based materials.

\section{Acknowledgement:-}

Author is very thankful to University Grant Commission, New Delhi to giving the Rajiv Gandhi National Fellowship to pursue Ph.D. Degree Award Letter No. F1-17.1/2013-14/RGNF-2013-14-SC-MAH-45715

Conflict of Interest:-Author has no conflict of interest 


\section{References:-}

1. Gounhalli S, Shantappa A, Hanagodimath SM. Studies on Mass Attenuation Coefficient, Effective Atomic Numbers and Electron Densities of Some Narcotic Drugs in the Energy Range 1KeV -100GeV. IOSR J App Phys. 2012; 2(4): 40-48.

2. Manjunatha, H.C., A study of gamma attenuation parameters in poly methyl methacrylate and Kapton. Radiat Phys Chem. 2016, http://dx.doi.org/10.1016/j.radphyschem.2016.01.024

3. El-Khayatt A, Ali A, Singh VP and Badiger NM. Determination of mass attenuation coefficient of low-Z dosimetric materials. Radiat Effects and Defects in Solids. 2014; 169(12): 1038-1044.

4. Pires L and Medhat M. Different methods of mass attenuation coefficient evaluation: Influences in the measurement of some soil physical properties. Applied Radiat and Isotopes. 2016; 111, 66-74.

5. Manohara S, Hanagodimath S. Studies on effective atomic numbers and electron densities of essential amino acids in the energy range $1 \mathrm{keV}-100 \mathrm{GeV}$. Nucl. Instrum. Methods Phys Res B. 2007; 258: 321-328.

6. Gowda S, Krishnaveni S, Yashoda T, Umesh T and Gowda R. Photon mass attenuation coefficients, effective atomic numbers and electron densities of some thermoluminescent dosimetric compounds. Pramana - J Phys. 2004; 63(3): 529-541.

7. Otto B. and Gür A. Determination of mass attenuation coefficients of concretes containingtincal concentrator waste. International J of Phys Sci. 2012; 7(44): 5861-5864.

8. Biswas R, Sahadath H, Mollah A. and Huq M. Calculation of gamma-ray attenuation parameters for locally developed shielding material: Polyboron. J Radiat Res Applied Sci. 2016; 9(1): 26-34.

9. Ekinci N, and Astam N (2007) Measurement of mass attenuation coefficients of biological materials by energy dispersive X-ray fluorescence spectrometry. Radiat Meas. 2007; 42(3): 428-430.

10. Berger MJ, Hubbell JH. (1987/1999) “XCOM: Photon Cross Section Database," Web Version 1.2, available at http:// Physics.nist.gov/XCOM. National Institute of Standards and Technology, Gaithersburg, MD 20899, USA (1999). Originally published as NBSIR87-3597 "XCOM: Photon Cross Section on a personal computer ."

11. Agostinelli S et. al. Geant4-A simulation toolkit. Nucl Instrum. Methods Phys Res A. 2003; 506: $250-303$.

12. Singh VP, Medhat ME, Badiger NM. Photon energy absorption coefficients for nuclear track detectors using Geant4 Monte Carlo simulation. Radiat Phys Chem. 2015; 106: 83-87.

13. Singh VP, Medhat ME, Shirmardi SP. Comparative studies on shielding properties of some steel alloys using Geant4, MCNP, WinXCOM and experimental results. Radiat Phys Chem. 2015; 106: 255-260.

14. Medhat ME and Singh VP. Geant4 monte carlo code application in photon interaction parameter of composite materials and composition with XCOM and experimental data. Indian J pure and applied phys. 2016; 54: 137143.

15. Hurtado S, Garc!1a-Le!on M, Garc!1a-Tenorio R. GEANT4 code for simulation of a germanium gamma-ray detector and its application to efficiency calibration. Nucl Instrum Methods Phys Res A. 2004; 518: $764-774$.

16. Amako k, Guatelli S, Ivanchenko VN, Maire M, Mascialino B, Murakami K, Nieminen P, Pandola L, Parlati S, Pia MG, Piergentili M, Sasaki T and Urban L. Comparison of Geant4 Electromagnetic physics models against the NIST reference data. IEEE Trans Nucl Sci 2005; 52: 910-918.

17. Pawar PP and Bichile GK. Studies on mass attenuation coefficient, effective atomic number and electron density of some amino acids in the energy range 0.122-1.330MeV. Radiat Phys Chem. 2013; 92: 22-27.

18. Kerur BR, Manjula VT, Lagare MT, Anil Kumar S. Mass attenuation coefficient of saccharides for X-rays in the energy range from $8 \mathrm{keV}$ to $32 \mathrm{keV}$. Radiat Meas. 2009; 44: 63-67.

19. Gowda S, Krishnaveni S and Gowda R. Studies on effective atomic numbers and electron densities in amino acids and sugars in the energy range 30-1333keV.Nucl. Instrum. Methods Phys Res B. 2005; 239(4): 361-369.

20. Hine GJ. The effective atomic number of materials for various gamma ray process." Phys Rev. 1952; 85: 725.

21. Creagh D. The resolution of discrepancies in tables of photon attenuation coefficients. ." Nucl Instrum Methods Phys Res A. 1987; 255(1-2): 1-16.

22. Kaçal M, Han I and Akman F. Measurement of mass attenuation coefficients by $\mathrm{Si}(\mathrm{Li}), \mathrm{NaI}(\mathrm{Tl})$ and $\mathrm{Cd}(\mathrm{Tl})$ detectors. Nucl Sci Tech. 2012; 59-69.

23. Bursalığlu E, Balkan B, Kavanoz H, Okutan M, Eçelli O, and Yaçin Z. Energy Absorption and Exposure Buildup Factors of Essential Amino Acids." BioMed Research International. 2014;

24. Bursalıoğlu E, İçelli O, Balkan B, Kavanoz H and Okutan M. Photon Atomic Parameters of Nonessential Amino Acids for Radiotherapy and Diagnostics. J Amino Acids. 2014; 1-10. 